\title{
On the Impact and Needs of Various Audience Groups from Space Analogue Outreach and Education Programmes
}

\author{
Daniel J. Robson ${ }^{1}$, Maria Grülich ${ }^{2}$, Ghanim Alotaibi ${ }^{2}$, Hannah Blackburn ${ }^{3}$, Nathan \\ Hadland $^{3}$, David Masaitis ${ }^{3}$, Veronica Trivino Herrero ${ }^{4}$, Natalia Larrea Brito ${ }^{5}$ \\ 1 Space School UK, 2 Space Generation Advisory Council, 3 Florida Institute of Technology, 4 \\ International Emerging Space Leaders, 5 International Space University SSP 2014
}

\begin{abstract}
The Mars Desert Research Base (MDRS) is a Mars analogue simulation facility in the Utah desert operated by the non-profit organisation, The Mars Society. The authors took part in Mission 205 to MDRS as part of the International Emerging Space Leaders (IESL) Crew in February 2019. The objectives included leadership development, surface navigation techniques, sample collection, astronomy and outreach. Some of Crew 205 had strong backgrounds in science communication and investigated outreach methods and protocols on "The Red Planet".
\end{abstract}

Some of the issues affecting current ISS also affect space analogue outreach programmes - limited data rates and bandwidth, physical remoteness, crew time/willingness, time difference/lag and other simulation conditions. These limitations can hamper the reach and effectiveness of outreach campaigns and are only likely to get worse during predicted future exploration missions.

Other differences exist between earth-based analogues and future Mars missions that can affect the receiving audience's engagement - in particular the perceived level of risk that the crew is under from environmental factors (such as weather or atmosphere), technical malfunction, isolation or the level of support the crew can receive if required. However, despite this, much can be gained by using analogue missions for effective space outreach.

This paper assesses the facets that can be best exploited to engage educators and students using the British Science Association Audience Model, without degrading the fidelity or validity of the simulation. It proposes improvements in premission outreach planning at MDRS that may be applicable for other analogue missions as well. MDRS.

Keywords-outreach; space; analogue; communications;

\section{INTRODUCTION}

The inspiration for this paper came from the authors' time serving on Crew 205 at the Mars Desert Research Station (MDRS) in Utah, USA. Crews experience two weeks of simulated Martian living, including the inability to leave habitat buildings without EVA suits, and limited supply/type of food and drink [1]. Crew 205 conducted experiments on leadership, psychology, navigation, ISRU plant growth experiments and geologic classification of substrates - alongside outreach activities - as it seemed an excellent opportunity to show that exciting space research can be done here on Earth, whilst under communication limitations "analogous" to those of ISS or interplanetary locations [2].

Most partner organisations receiving outreach were secured by the personal and professional relationships of Crew 205 members, with outreach "products" being shared through digital media both during and after the mission, including daily photo updates, journalism reports, and the posting of crew bios - all encouraged by the Mars Society. Crew 205 also posted "shout-out" photos (posed photos with a sign, prop or caption mentioning a partner organisation or specific person), encouraged Facebook audience interactions through photos and posting comments, photos with the Crew's puppet mascot and recorded interviews/short lessons on Mars exploration topics. The crew also utilised Facebook, Twitter and Instagram pages, each shared by crew members and/or universities to attract an audience prior to the mission's onset.

The public Facebook page generally received the most audience attention, with the largest following $(n>400)$ and significant crew/follower interaction on posted content, usually with good commitment (comment, questions and compliments on posts as opposed to just "likes") [3].

One problem Crew 205 faced was that while missions to space or high-profile analogues such as Mars 500, Biosphere 2, HI-SEAS and Antarctic Bases can generate lots of public interest, small bases like MDRS appear to be lesser known. Results showed that most social media followers were family, university friends or colleagues (i.e. people who already knew about the mission or were studying/working in STEM or spacerelated fields). The same passions that drive STEM professionals make them an endemic audience demographic, therefore it is imperative for analogue participants to consider other audiences, particularly amongst educational bodies.

Currently, unless someone knows a crew member or is within their reach on social media, they are unlikely to be aware 
of missions or outreach at analogues like MDRS, unless they are researching similar topics on the internet. It is often overlooked that students and graduates at MDRS (and other analogues) make excellent science communicators, but currently face difficulties in sharing their science with the broader public and efficiently utilising their mission for outreach.

Many studies have shown that school children and teachers are excellent target audiences for STEM and space outreach [4][5]. They are an impressionable audience; able to appreciate real-world applications of space technology and the relevance it has in their societies. They would also be particularly inspired by how young people (most MDRS crews are $\mathrm{HE}$ or postgraduate age) can get involved and be a vital part of research into spaceflight and human life on other worlds.

Young people are an important audience for space / STEM outreach - and space exploration has the added benefit of being an exciting subject to teach curriculum STEM in an engaging manner. Both the UK Space Agency and ESA Education have repeatedly stated their awareness and commitment to using space as a tool to better teach STEM subjects and ensure a continued and growing supply to the space and STEM workforce [5][6].

Safeguarding laws (preventing unsupervised contact between pupils and crew members) ensure that all parties are protected, however require extra steps to be taken before outreach can happen in schools [7]. Crews, for instance, should not be encouraging children in schools to follow their own or even all-crew/mission specific social media profiles. Crews can also lack experience on topics that are suitable for school education and audience opinion on activity types. These limitations dull the impact of outreach activities from analogues like MDRS, but school children and teachers have rarely been asked exactly what they would like to see and how they would like it communicated.

\section{SURVEY MeTHODOLOGY FOR SCHOOL GROUPS}

Analogue bases can be scientifically valid locations for testing technologies, human and exploration procedures [8] and when bases are placed in locations geologically and appearance-wise analogous to their target destination they are a great opportunity for outreach. For example, spacesuits such as the OeWF Aouda X were evaluated for temperature control in wind tunnels and ovens, but also in analogue bases like the Omani desert - a much more appealing and newsworthy demonstration from an outreach point of view [9][10].

This study was carried out to find which outreach activities and topics pupils are most interested in seeing MDRS crews complete - and how they would like to hear about it. In postmission school visits, the authors gave a 25 -minute talk on space exploration and the use of space analogues to prepare for life on the Moon or Mars; students then completed detailed surveys. Teachers and secondary school students were asked which methods of sharing outreach information they preferred (social media sites, blogs, emails etc) and then all groups were surveyed for their opinions on certain suggested outreach activities and topics. The research also investigated whether pupil preference changed due to factors such as age, gender or British Science Association Audience Group.

The sample was limited by time and resources and none of the authors are qualified or experienced sociologists, so the data merely gives an initial understanding of pupil / teacher preference, requiring substantiation. It nevertheless adds to our knowledge of space/STEM outreach and can be used to improve current strategies. The authors' personal school contacts and the STEM Ambassador Scheme (via Leicestershire Education Business Company, LEBC) were used to secure sample audiences [11]. Altogether circa 400 pupils from 7 schools (see table below) supplied data quantifying their various views and preferences.

TABLE 1. SCHOOL TYPES, CLASSES AND STUDENTS SURVEYED

\begin{tabular}{|c|c|c|c|}
\hline School Type & $\begin{array}{c}\text { Classes } \\
\text { Involved }\end{array}$ & Students & Staff \\
\hline \multirow[t]{2}{*}{$\begin{array}{l}\text { State Secondary } \\
\text { (Leicester) }\end{array}$} & $\begin{array}{l}\text { Y10 Separate } \\
\text { Sciences (top } \\
\text { set) \& visiting, } \\
\text { interested Y9s) }\end{array}$ & $15 \mathrm{~m}, 25 \mathrm{f}$ & $\begin{array}{l}1 \text { Physics Teacher } \\
2 \text { UG Physics } \\
\text { Student Teaching } \\
\text { Placements }\end{array}$ \\
\hline & $\begin{array}{c}\text { Y10 Separate } \\
\text { Sciences (set 2) }\end{array}$ & $12 \mathrm{~m}, 2 \mathrm{f}$ & 1 Physics Teacher \\
\hline \multirow[t]{2}{*}{$\begin{array}{l}\text { Private Secondary } \\
\text { (Newcastle) }\end{array}$} & $\begin{array}{l}\text { Y10 Separate } \\
\text { Sciences (top } \\
\text { set) }\end{array}$ & $15 \mathrm{~m}$ & $\begin{array}{c}1 \text { Head of Physics } \\
1 \text { School } \\
\text { Communications } \\
\text { Officer }\end{array}$ \\
\hline & $\begin{array}{l}\text { Y8 Chemistry } \\
\text { (unsetted) }\end{array}$ & $17 \mathrm{f}$ & $\begin{array}{c}1 \text { Chemistry } \\
\text { Teacher } \\
1 \text { Head of Science }\end{array}$ \\
\hline $\begin{array}{l}\text { State Secondary - } \\
\text { visiting Y8's to } \\
\text { below Primary } \\
\text { (Hinckley) }\end{array}$ & $\begin{array}{l}\text { Visiting Y8's } \\
\text { (had run a } \\
\text { voluntary space } \\
\text { outreach } \\
\text { workshop for } \\
\text { primary pupils) }\end{array}$ & $5 \mathrm{~m}, 5 \mathrm{f}$ & $\begin{array}{c}1 \text { Year } 8 \text { Biology } \\
\text { Teacher } \\
1 \text { Year } 8 \text { TA }\end{array}$ \\
\hline \multirow[t]{2}{*}{$\begin{array}{l}\text { State Primary } \\
\text { (Hinckley) }\end{array}$} & $\begin{array}{c}\text { Entire Y5 in an } \\
\text { assembly }\end{array}$ & $\begin{array}{c}22 \mathrm{~m}, 32 \mathrm{f} \\
10\end{array}$ & 1 Year 5 Teacher \\
\hline & $\begin{array}{c}\text { Entire Y6 in } \\
\text { same assembly }\end{array}$ & $\begin{array}{c}27 \mathrm{~m}, 28 \mathrm{f} \\
1 \mathrm{o}\end{array}$ & 1 Year 6 Teacher \\
\hline \multirow[t]{3}{*}{$\begin{array}{l}\text { State Primary } \\
\text { (Leicestershire) }\end{array}$} & Y4 Class & $12 \mathrm{~m}, 14 \mathrm{f}$ & $\begin{array}{l}1 \text { Head of Science } \\
\& \text { Y4 Teacher }\end{array}$ \\
\hline & Y5 Class & $\sim 30$ & Surveys en route \\
\hline & Y6 Class & $\sim 30$ & Surveys en route \\
\hline \multirow[t]{3}{*}{$\begin{array}{l}\text { State Primary } \\
\text { (Leicester) }\end{array}$} & Y3 Class & $\begin{array}{l}\sim 30 \text { (not } \\
\text { included in } \\
\text { results) }\end{array}$ & $\begin{array}{l}1 \text { Year } 3 \text { Teacher } \\
\text { (not included in } \\
\text { results) }\end{array}$ \\
\hline & Y5 Class (1) & $11 \mathrm{~m}, 13 \mathrm{f}$ & 1 Year 5 Teacher \\
\hline & Y5 Class (2) & $10 \mathrm{~m}, 18 \mathrm{f}$ & 1 Year 5 Teacher \\
\hline \multirow{2}{*}{$\begin{array}{l}\text { State Primary } \\
\text { (Newcastle) }\end{array}$} & Y5 Class (1) & \multirow{2}{*}{$\begin{array}{c}26 \mathrm{~m}, 30 \mathrm{f}, \\
2 \mathrm{o} \\
\text { combined }\end{array}$} & 1 Year 5 Teacher \\
\hline & Y5 Class (2) & & 1 Year 5 Teacher \\
\hline $\begin{array}{l}\text { Total } 6 \text { Schools } \\
\text { (plus } 1 \text { still } \\
\text { pending) }\end{array}$ & \multicolumn{2}{|c|}{$\begin{array}{l}\text { Secondary: } 47 \mathrm{~m} \& 49 \mathrm{f} ; \\
\text { Primary: } 108 \mathrm{~m}, 135 \mathrm{f}, 4 \text { other- } \\
\text { gendered, plus c. } 90 \text { other } \\
\text { primary pupils reached but } \\
\text { no data used }\end{array}$} & $\begin{array}{l}18 \text { members of } \\
\text { school staff, plus } \\
\text { another } 3 \\
\text { reached but no } \\
\text { data used } \\
\end{array}$ \\
\hline
\end{tabular}


First, some observations and disclaimers must be made. All year 10 classes were separate science GCSE groups (had elected to do the greatest amount of science subjects for GCSE) so were a self-selecting group more likely to be interested in science than peers. The second (smaller) year 8 group were also self-selecting as "interested in science", having planned and run a small workshop on astronaut suits during their school's STEM week and were invited back for this presentation. One secondary school was a private day-school (including the remaining year 8 class) requiring an entrance exam. In all, the secondary school data was useful for studying pupil/teacher attitudes to STEM, space, and analogue outreach activities, but should not be taken as representative of the general UK school population.

The primary schools were more representative of the UK pupil population - all were state schools and standard classes (most year $5 \mathrm{~s}$ had Space as part of the National Curriculum that year). However, two schools were on a self-elected emailing list as part of LEBC (see above) and, when contacted about a possible Crew 205-member visit, offered an invite. Perhaps this indicates encouragement for pupils to be interested, or participate in, science beyond the normal curriculum i.e. the school and its pupils are potentially more interested in science than the average. A further primary school had a science programme supported by a STEM activity week (including workshops from visiting Year 8s) involving a space industry employee and ex-pupil - indicating that this school may encourage interest in science above the national average.

All surveys were anonymous - and worded slightly differently for primary students to make the language more accessible. Students scored their level of interest out of 10 in different crew outreach activities and in STEM-related topics where space analogues could act as real-world examples. For teachers and secondary pupils, the focus was in ways they would prefer the crew to communicate their outreach information. There were also questions establishing pupil demographics, personal views on STEM subjects / space exploration as a learning topic and spaces allowing written suggestions to be made.

Collected data was analysed by comparing the means and standard deviations (s.d.) of opinions on questions. If the mean score for an outreach option is high, on average students think well of it. If the s.d. is low, the group generally agree on this opinion. High mean and low s.d. suggests topics desired for classroom use, without disenfranchising students who favour it less. More data would be required to assign statistical weight between these factors, so this paper values them equally.

Finally, pupils identified themselves using an edited version British Science Association's (BSA) Audience Model [12] to see if their level of interest in science affected the kind of activities they preferred to see at space analogues. The BSA asks participants aged $16+$ to identify which of four statements they identify with most. The categories being Professionals: "I enjoy science and intend to take science-based subject choices in later school and see myself enjoying a career related to it", Engaged: "I enjoy science and while I can see myself taking some science subject choices, I can't see myself pursuing a career in it", Inactive: "I enjoy learning about certain bits of science at school or through TV shows, books, movies etc, but I can't see myself choosing many science subject choices or a career in it," and Not Interested: "Science is definitely not for me."

These questions had to be slightly repurposed for young students to improve comprehension. In this paper, BSA audience groups are often described as being 1-4, with 1 being "professional" (the highest natural interest in science), for statistical convenience and clarity - even though a (necessary) deviation from the standard BSA Audience Model.

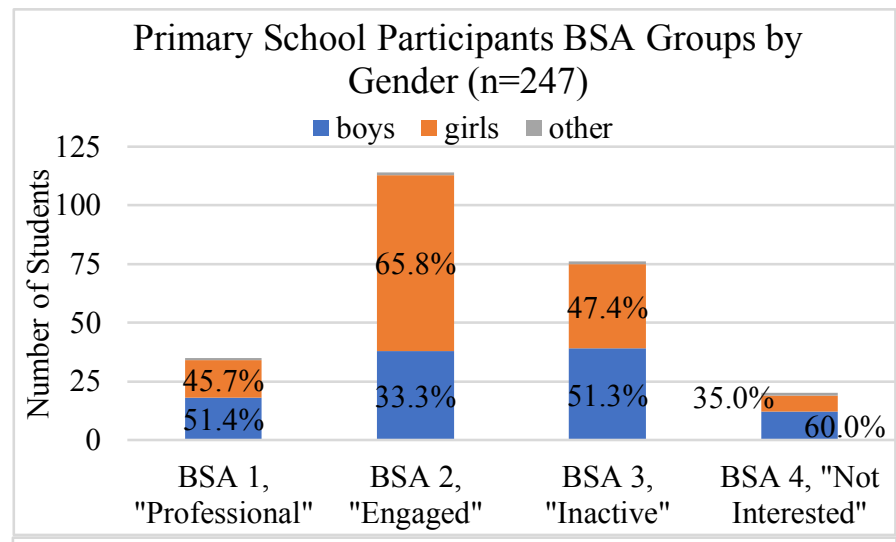

Fig. 2. Demographics of primary school survey participants. A total of $108 \mathrm{~m}$, $135 \mathrm{f}$ and $4 \mathrm{o}$ pupils' results were used.

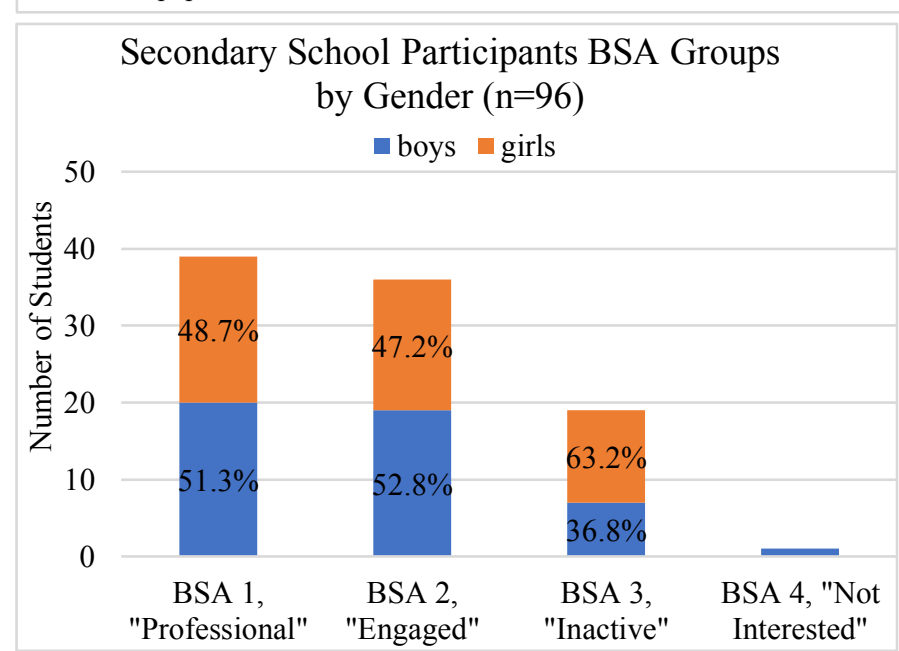

Fig. 3. Demographics of secondary school survey participants. A total of $47 \mathrm{~m}$ and 49 f pupils' results were used.

In this respect it was worth reviewing students' BSA audience group scores to determine if a pattern could be determined before analysing results. This was done to establish if the scheme used was appropriate (or not) as a measure of pupils' self-assessed engagement. 


\section{HEADLINE RESUlTS}

When comparing participants' BSA groups to their "engagement scores" there was a trend for "higher" BSA groups to show higher engagement with STEM. The R-squared regression line statistic for secondary and primary pupils is $30.5 \%$ and $29.1 \%$, respectively, showing an expected similarity between the groups, supporting that BSA groups are useful for comparing sampled school groups. The standard deviation of "engagement score" answers of BSA groups' increased as the groups progress from 1-4, across both age groups.

Interestingly, a pupil's BSA group was a stronger indicator of their opinions across multiple results than their gender and this is true for both student age groups. This included their general interest in science and outreach activity preference. Boys of both age groups had lower s.d. variations than girls across all categories of questions (apart from secondary girls' "general interest in science" s.d., which was significantly lower).

Notably, secondary students gave lower mean values, but with lower s.d.'s, than primaries on almost every question. It proved difficult to determine why, but possibilities include increased cynicism among older students about the merit and application of space exploration/analogues to their daily lives, or perhaps that their interest has moved away from simple curiosity about life in space towards difficult technical aspects. It also appeared that younger pupils excited about the talk, may have awarded high scores (all 10/10s) based on immediate emotional reaction, rather than the more measured and analytical scoring demonstrated by secondary school students.

Reviewing participant opinions of outreach activities:

- The appetite for "Daily Journalism Pieces" had one of the lowest overall mean scores for both primary and secondary pupils and teachers (although its s.d. was high, indicating a large spread of opinion). This spread was particularly so for primary pupils - perhaps because they had different interpretations of what the reports' content, length or complexity would be like.

- Daily photos scored well across all participant groups, with a low s.d. This is a positive indicator for analogue crews, as daily photo updates are easy to produce and distribute, and are encouraged by the Mars Society.

- Q\&A videos also scored very highly. These were notably stated in the survey to not be "video calls", but rather short videos of crew members answering questions emailed in - something that real astronauts regularly do in outreach sessions both in space and on Earth (personal research).

- Primary pupils had a high appetite for "shout-outs" using signs in photos or videos, but secondary pupils disagreed; these answers had some of the lowest means. Both data sets had low s.d. scores - i.e. these opinions seem well agreed. Teachers were split, some rating shout-outs highly, while others voted them the worst - possibly because they weren't clear what a "shout-out" involves or saw it as problematic. Some of Crew 205's "shout-outs" were to individuals or too colloquial, whilst others were to schools, with receiving schools very pleased indeed.

- Secondary pupils rated outreach activities using "mascots" (such as Gus, Crew 205's mascot puppet) lower than primary students, both in absolute score and relative to other ideas.

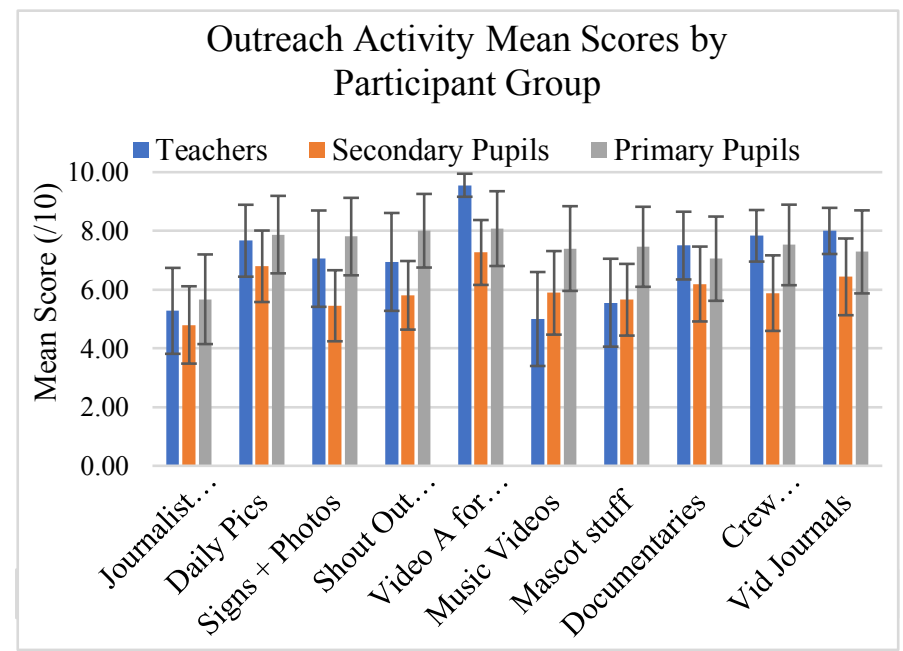

\begin{tabular}{|c|c|c|c|c|c|c|}
\hline & \multicolumn{2}{|c|}{ Teachers } & \multicolumn{2}{|c|}{$\begin{array}{l}\text { Secondary School } \\
\text { Pupils }\end{array}$} & \multicolumn{2}{|c|}{$\begin{array}{l}\text { Primary School } \\
\text { Pupils }\end{array}$} \\
\hline $\begin{array}{l}\text { Outreac } \\
\mathrm{h} \\
\text { Activity }\end{array}$ & Mean & $\begin{array}{c}\text { Standard } \\
\text { Deviation }\end{array}$ & Mean & $\begin{array}{c}\text { Standard } \\
\text { Deviation }\end{array}$ & Mean & $\begin{array}{c}\text { Standard } \\
\text { Deviation }\end{array}$ \\
\hline $\begin{array}{c}\text { Journali } \\
\text { st } \\
\text { Reports }\end{array}$ & 5.28 & 2.93 & 4.80 & 2.63 & 5.67 & 3.05 \\
\hline $\begin{array}{l}\text { Daily } \\
\text { Photos }\end{array}$ & 7.67 & 2.45 & 6.80 & 2.43 & 7.88 & 2.64 \\
\hline $\begin{array}{l}\text { "Shout- } \\
\text { out" } \\
\text { signs } \\
\text { and } \\
\text { photos }\end{array}$ & 7.06 & 3.28 & 5.45 & 2.42 & 7.81 & 2.64 \\
\hline $\begin{array}{l}\text { "Shout- } \\
\text { out" } \\
\text { videos }\end{array}$ & 6.94 & 3.33 & 5.81 & 2.34 & 8.01 & 2.51 \\
\hline $\begin{array}{c}\text { Videos } \\
\text { answeri } \\
\text { ng } \\
\text { question } \\
\text { s } \\
\text { submitte } \\
\text { d by } \\
\text { class }\end{array}$ & 9.56 & 0.78 & 7.27 & 2.21 & 8.08 & 2.55 \\
\hline $\begin{array}{c}\text { Music } \\
\text { Videos }\end{array}$ & 5.00 & 3.20 & 5.89 & 2.85 & 7.40 & 2.88 \\
\hline $\begin{array}{l}\text { Mascot } \\
\text { Photos/ } \\
\text { Videos }\end{array}$ & 5.56 & 2.99 & 5.66 & 2.44 & 7.46 & 2.73 \\
\hline $\begin{array}{c}\text { Docume } \\
\text { ntaries }\end{array}$ & 7.50 & 2.31 & 6.19 & 2.55 & 7.05 & 2.87 \\
\hline $\begin{array}{c}\text { Crew } \\
\text { Intervie } \\
\text { ws }\end{array}$ & 7.83 & 1.76 & 5.88 & 2.57 & 7.52 & 2.74 \\
\hline $\begin{array}{c}\text { Crew } \\
\text { Video } \\
\text { Journals }\end{array}$ & 8.00 & 1.57 & 6.44 & 2.61 & 7.29 & 2.83 \\
\hline
\end{tabular}


BSA group analysis of these activity opinions showed that:

- "Higher" BSA groups generally scored every activity and teaching topic with a higher mean than "lower" groups. However, within each group, activity scores moved relative to each other (i.e. their rank changes); this is an important insight when tailoring outreach strategies and activities to particular audiences.

- In primary schools, the "uninterested" group 4 mostly favoured outreach activities less favoured by the other groups - notably music videos, documentaries and crew interviews (only documentaries also rated relatively highly with BSA Group 1).

When results were filtered for gender, data indicates that:

- Mean scores for most outreach activities were higher amongst girls than boys (true for both age groups).

- The s.d. values for boys across both school groups tend to be lower than girls, for all outreach activities.

- For outreach activity results, s.d. values grouped by gender were higher than those of their BSA groups (indicating greater agreement) supporting hypotheses that the BSA Audience Model can be applied to children and useful data still extracted.

- Gender groups also had higher s.d. deviations for their "general interest in science" than most BSA groups'.

When sources (channels) for outreach are compared:

- Many teachers (especially primary) gave social media sites very low scores, citing the need to instruct pupils that these are forbidden at their age (in accordance with many social media site Terms \& Conditions) and forbidden from using them at school - also stressing safeguarding laws preventing students interacting directly with crew members.

- Twitter (despite a significant s.d.) was the highest mean-rated social media preference of teachers - but Instagram was the highest among secondary pupils also reflecting their preferences for outreach activities using photos and videos, rather than words / articles.

- Both groups also expressed a respectably high mean opinion for using a website (a crew-blog or analogue base website) for updates, with this view also having some of the lowest s.d. values among both groups.

\begin{tabular}{|c|c|c|c|c|}
\hline \multirow[b]{2}{*}{ Outreach Source } & \multicolumn{2}{|c|}{ Teachers } & \multicolumn{2}{|c|}{$\begin{array}{l}\text { Secondary School } \\
\text { Pupils }\end{array}$} \\
\hline & Mean & $\begin{array}{l}\text { Standard } \\
\text { Deviation }\end{array}$ & Mean & $\begin{array}{l}\text { Standard } \\
\text { Deviation }\end{array}$ \\
\hline $\begin{array}{l}\text { Analogue base } \\
\text { own website }\end{array}$ & 7.28 & 2.72 & 5.04 & 2.62 \\
\hline Crew blog & 8.00 & 2.47 & 4.67 & 2.79 \\
\hline Facebook & 4.22 & 3.51 & 3.95 & 2.71 \\
\hline Twitter & 6.22 & 3.92 & 4.48 & 2.92 \\
\hline Instagram & 4.39 & 3.97 & 6.98 & 2.95 \\
\hline $\begin{array}{l}\text { Updates from your } \\
\text { School }\end{array}$ & 6.17 & 3.07 & 6.33 & 2.76 \\
\hline
\end{tabular}

\begin{tabular}{|l|cccc|}
\hline Email Newsletters & 7.39 & 2.17 & 4.83 & 2.80 \\
\hline $\begin{array}{l}\text { Fig. 6. Mean Results and Standard Deviations for participant group opinions } \\
\text { of suggested outreach communication sources }\end{array}$ &
\end{tabular}

Given these results and comments, teachers should act as online intermediaries for analogue crews, passing updates to students. Safeguarding rules mean that pupils should not contact crew members directly, or vice versa [7]. Websites that do not have a feature allowing direct contact (such as a blog without contact details, or official base website) could be shown for students to research in their free time, if approved by the teacher. Sites such as Twitter would be beneficial for analogue crews (requiring less planning and maintenance than a blog) but have messaging capabilities, so should be forbidden without an appropriate go-between. The MDRS website has a section available for crews to instruct "Mission Control" to update with daily photos and journalist reports, which anyone can then visit. But the website is significantly less user-friendly than either Twitter or a dedicated blog.

\section{On outreach topics:}

- The top interest for both pupil groups was EVA activities, whereas the teachers scored the EVAs second lowest (though with a significantly large s.d.). While EVAs are exciting to students, teachers may see them as inapplicable to the current curriculum, or may not have the knowledge or time to plan and deliver lessons based around them.

- Teachers scored renewable energy and recycling very highly as examples of how analogue bases can benefit real world research (with both means over 8 and the lowest s.d. scores, too). This is helpful from a space perspective; long-term space infrastructure and closed loop systems are increasing priorities as exploration mission plans shift to more sustainable and long-term technology) - and creates an important link to issues critical to curriculum education and future society.

- Like teachers, both students groups rated renewable energy highly as a topic for analogue base outreach but, interestingly, recycling was in the lower half of ranked topics across both groups.

\begin{tabular}{|c|c|c|c|c|c|c|}
\hline \multirow[b]{2}{*}{ Outreach Topic } & \multicolumn{2}{|c|}{ Teachers } & \multicolumn{2}{|c|}{$\begin{array}{l}\text { Secondary } \\
\text { Pupils }\end{array}$} & \multicolumn{2}{|c|}{ Primary Pupils } \\
\hline & Mean & $\begin{array}{l}\text { Standard } \\
\text { Deviation }\end{array}$ & Mean & $\begin{array}{l}\text { Standard } \\
\text { Deviation }\end{array}$ & Mean & $\begin{array}{l}\text { Standard } \\
\text { Deviation }\end{array}$ \\
\hline Recycling & 8.94 & 1.34 & 6.35 & 2.19 & 7.69 & 2.66 \\
\hline Psychology & 4.65 & 2.57 & 6.44 & 2.59 & 7.84 & 2.70 \\
\hline $\begin{array}{l}\text { Plants \& } \\
\text { Photosynthesis }\end{array}$ & 6.47 & 2.72 & 5.86 & 2.06 & 7.44 & 2.65 \\
\hline $\begin{array}{l}\text { Renewable } \\
\text { Energy }\end{array}$ & 8.06 & 2.41 & 6.64 & 2.24 & 8.03 & 2.53 \\
\hline EVA/Spacewalks & 5.47 & 3.54 & 7.08 & 2.53 & 8.61 & 2.26 \\
\hline $\begin{array}{l}\text { Orienteering/Map } \\
\mathrm{s}\end{array}$ & 6.41 & 3.10 & 5.89 & 2.50 & 8.34 & 2.34 \\
\hline
\end{tabular}




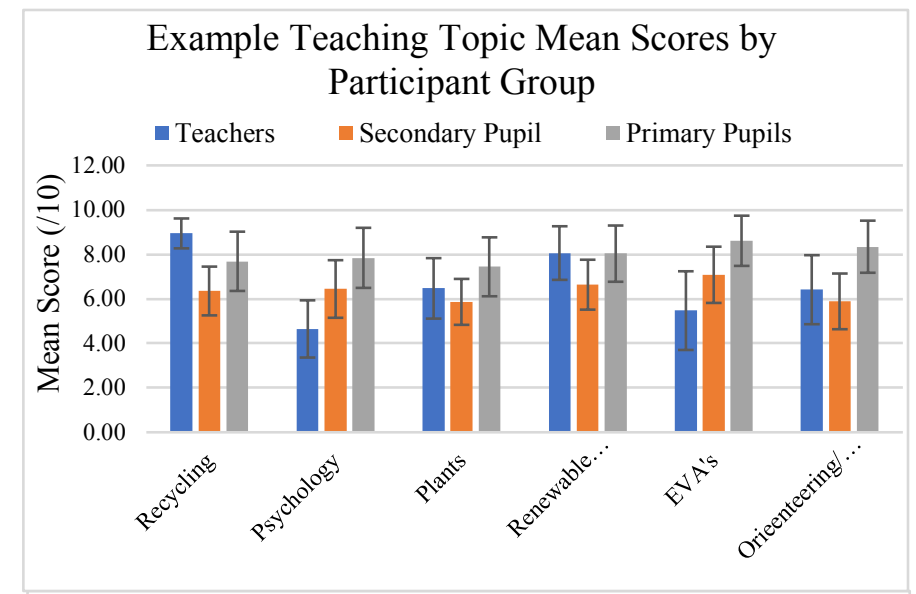

Fig. 8. Graphical presentation of the data in Fig. 7. (above)

\section{Discussion Of Results}

When considering the data obtained, ambiguity is a general issue i.e. "documentaries" could be short (a few minutes on a focused topic) or longer (tens of minutes on daily life in the base). "Crew interviews" could be informal and entertaining, or formal, based on promoting scientific purposes. Similarly, with EVA, there could be big differences between what pupils expect and what the crew can deliver, so improvements should be made to the survey by reviewing the pre-survey presentation to filter out instances where students might be misled or confused.

Some results support the compatibility of the BSA Audience Model within this study, e.g. group 1 secondary pupils support using analogue base websites ( $3^{\text {rd }}$ highest mean score) but the mean for this progressively decreased across other groups, suggesting the most scientifically interested students were most committed to searching for analogue information in free time.

Teachers are acutely aware of the need to balance outreach with safeguarding laws and preferred methods where students had no direct contact with analogue crews or vice versa (i.e. outreach activities requiring teachers as an intermediate point of contact). Schools would therefore need prior knowledge of the mission to increase the effectiveness of outreach. Building an engaging outreach relationship between crew members and schools could be achieved in a number of ways - there were suggestions for pre-mission school visits; students providing items for use at analogue bases; students designing or choosing parts of an experiment to be performed; or a competition to design a crew's mission patch.

The question of how to identify interested schools should also be discussed; some follow science communications social media channels and others will be open to direct contact - but it may prove preferable for analogues to use intermediaries like STEM education charities (just as this study used LEBC), thus protecting both analogues and schools from safeguarding issues. Analogue crews would benefit from having a blog, website or social media page with published pre-mission details, to establish mission credibility and explain how schools and other institutions could get involved.

A repeated suggestion from teachers and students alike was to film and explain an experiment being performed at the base. One secondary physics teacher even suggested letting students design experiments for the crew to perform on site. This could involve on-site comparative experiments that could be tested against student-conducted "control" experiments performed in the classroom, as well as novel experiments explicitly unique to the analogue environment. Both techniques would demonstrate the analogue's scientific viability as a wider educational opportunity.

Another outreach activity with high mean scores and low s.d. values across both school groups and teachers, were Q\&A videos. Crews should avoid audiences believing this to be a live exchange, as most analogues (including MDRS) prohibit this. Despite this being stated clearly on the survey, some respondents' notes suggested they mistakenly interpreted it as live video calls. If the suggested technique were utilised, it would be imperative that crews establish contact with interested audience groups prior to mission execution to establish appropriate lines of questioning and deliverable deadlines.

\section{CONCLUSIONS}

The results indicate a range of opinions and preferences for outreach activities at space analogues like MDRS; some match across distinction lines and between groups with s.d. data that proves them to be agreed on.

Twitter or blog-based websites were the highest ranked outreach medium between crew and schools, but safeguarding rules must be observed. Suggested techniques include the use of teachers as intermediaries with no direct crew-student contact outside of faculty supervision, and the use of STEM Outreach intermediaries as recruitment partners for crews. There are varying opinions on current MDRS outreach activities (Daily Photos and Journalist Reports), although image-related material such as photos and videos, are usually preferred to written reports.

The high interest of pupils and teachers in Renewable Energy technology is advantageous as this is an important research topic for analogue bases - many of which are studying systems which recirculate ECLSS resources as much as possible for improved long-term sustainability [8]. Related subjects such as recycling, despite slightly more mixed results, can also feature if desired - explaining how technology being used or tested at space analogues can be useful for terrestrial life, too.

Given strong student interest, analogue crews and teachers should consider the best approaches of making EVA material relevant to the curriculum. This will require careful planning to optimise fidelity of crew produced products and acutely target material to the desired audience groups (e.g. at MDRS, good 
voice recordings of crew may not be achievable due to helmets being in the way and EVA time and data restrictions can lower the quality/number of images and videos the crew are able to process and upload).

There is a strong interest amongst pupils and teachers for space outreach - so managers of analogue stations should encourage and guide crews accordingly. Pro-active planning and materials give analogues bases a great opportunity to maximise outreach results. Particularly to school and teacher audiences, through certain social media or website channels and using preferred outreach products whilst safeguarding systems are used. While these suggestions are not presently accurate enough to be reliably applied to entire school populations, the authors hope the data lends some insight to aspiring crews' outreach programmes.

\section{ACKNOWLEDGMENT}

The authors would like to acknowledge the staff and students of the schools visited for their gracious attention and support, the Mars Society for hosting MDRS Mission 205, and the STEM Ambassador Scheme (via Leicestershire Education Business Company). They are most grateful for the time and support of family and friends who were critical in every aspect of this mission from initial mission planning to the finalising of this manuscript.

\section{REFERENCES}

[1] The Mars Society, "The Mars Deser Research Station Mission", http://mdrs.marssociety.org/about/

[2] MDRS Crew 205, "Final Mission Summary", https://mdrs.marssociety.org/2019/02/23/final-mission-summary-crew$\underline{205 /}$

[3] MDRS Crew 205, "IESL Crew 205 Facebook Page", https://www.facebook.com/IESLcrew205/?tn-str=k*F, Accessed Jan 2019

[4] National Audit Office, "Delivering STEM (science, technology, engineering and mathematics) skills for the economy", $17^{\text {th }}$ Jan 2018 , HC 716

[5] UKSA (Gov.uk), "UK Space Agency Education, Skills and Outreach Strategy",https://assets.publishing.service.gov.uk/government/uploads/s ystem/uploads/attachment_data/file/516474/UK_Space_Agency_Educat ion Strategy 2016.pdf, April 2016, Accessed 31 ${ }^{\text {st }}$ July 2019

[6] M. Talevi, "ESA Education Activities", 7th CCI Co-location meeting, 6 October 2016, ESRIN, Italy

[7] NSPCC, "Online Safety and Social Media", https://learning.nspcc.org.uk/safeguarding-child-protection/onlinesafety-for-organisations-and-groups/, Accessed 30 ${ }^{\text {th }}$ July 2019

[8] I. Lea Schlacht et.al., "Space Analog Survey: Review of Existing and New Proposal of Space Habitats with Earth Applications", 46th International Conference on Environmental Systems, 10-14 July 2016, Vienna, Austria (ICES-2016-367)

[9] OeWF, "AMADEE-18 Mission Press https://hive.oewf.org/cloud/index.php/s/c51IuxSiSICe5QU\#pdfviewer

[10] OeWF, "Aouda Test Campaign 17A Completed", https://oewf.org/en/2017/01/aouda-test-campaign/, $\quad 7^{\text {th }} \quad$ Jan 2017 , Accessed 30 ${ }^{\text {th }}$ July 2019

[11] Leicestershire Education Business Company, "STEM Ambassadors", https://www.leics-ebc.org.uk/employers/stem-ambassadors

[12] British Science Association, "The BSA's Audience Model", https://www.britishscienceassociation.org/Handlers/Download.ashx?ID MF=fff24e64-6f1b-4a30-bace-da84b0546bf1 